\title{
TỔ HỢP BẤT LỢI CỦA GIÓ MÙA TÂY NAM VÀ THỦY TRIỀU ĐẾN AN TOÀN ĐÊ BIỂN TÂY NAM BỘ VÀO NGÀY 3 THÁNG 8 NĂM 2019
}

\author{
Nguyễn Xuân Hiển ${ }^{1}$, Lê Đức Quyền ${ }^{1}$
}

Tóm tắt: Nước dâng do gió mùa ảnh hương đến an toàn của các công trình ven biển, đặc biệt trong thời kỳ triều cuờng. Đầu tháng 8 năm 2019, đê biển ở khu vực ven biển huyện Trần Văn Thời bị sóng đánh tràn qua đê, gây sạt lở nghiêm trọng, ảnh hwởng đến an toàn đê, gây thiệt hại cho hàng chục nghìn ha lúa và cuộc sống của hàng chục nghìn hộ dân bị ảnh hưởng. Mô hình số trị được áp dụng để tính toán và đánh giá đóng góp của nước dâng do gió mùa Tây - Nam, nước dâng do sóng và thủy triều đến mực nước tổng công gây tràn đê cho đói với các điểm ven biển ở khu vực biển Tây Nam Bộ trong đọt gió mùa đầu tháng 8 năm 2019. Kết quả cho thấy, mưc nuoóc tổng cộng cao nhất trong đợt gió mùa tù̀ ngày 2 đến tháng 8 năm 2019 ở khu vục ven biển Tây Nam Bộ lên tới $2 m$. Trong đó nước dâng do gió mùa đóng góp tù 0,35-0,5m, nước dâng do sóng tù̀ 0,1-0,25m, mưc nuớc triều là 1,3 - 1,6m. Mực nước biển dâng cao do các nguyên nhân trên kết hợp với sóng tại khu vục cao tù̀ 2 - 2,5m là nguyên nhân chính gây tràn đê tại khu vục.

Từ khóa: Nước dâng tổng cộng, nước dâng do gió mùa, nước dâng do sóng, chiều cao sóng, thủy triều.

Ban Biên tập nhận bài: 12/05/2019 Ngày phản biện xong: 18/7/2019 Ngày đăng bài: 25/08/2019

\section{Mở đầu}

Các nghiên cứu về nước dâng do gió mùa ít được quan tâm hơn so với nước dâng do bão vì gió mùa gần như là hiện tượng xảy ra thường xuyên và mức dâng không lớn [1]. Tuy nhiên, nước dâng do gió mùa lại đặc biệt nguy hiểm nếu gió mùa với cường độ cao xảy ra trong thời kỳ triều cường. Chính vì vậy, tại một số quốc gia trên thế giới, nước dâng do gió mùa được đưa vào dự báo nghiệp vụ như Nhật Bản, Hoa Kỳ, $\mathrm{Na} U y . .$. , với quy trình được thiết lập 1 hoặc 2 phiên dự báo trong một ngày tùy theo cường độ của các đợt gió mùa. Thông tin về nước dâng do gió mùa được phát cảnh báo kết hợp với những ngày có thủy triều cao [11-13].

Khu vực biển Việt Nam, vào mùa đông chịu tác động của gió mùa đông bắc và vào mùa hè là gió mùa tây nam. Các trường gió đông bắc thường có cường độ lớn và độ ổn định hoạt động cao hơn so với các trường gió mùa tây nam [10].

${ }^{1}$ Viện Khoa hoc Khi tượng Thủy văn và Biến đổi khi hậu

Email:nguyenxuanhien79@gmail.com
Tại Việt Nam cũng đã có khá nhiều các nghiên cứu liên quan đến nước dâng do gió mùa. Theo Phạm Ngọc Ninh (2003), những đợt gió mùa mạnh (cấp 6,7$)$ và kéo dài $(2$ - 3 ngày hoặc các đợt gió mùa liên tiếp) cũng gây nên nước dâng đáng kể, nước dâng do gió mùa thường có độ lớn trong khoảng từ 10 - 40 cm [1]. Phạm Văn Huấn (2007) đã đánh giá dao động dâng rút mực nước biển Đông trong hai trường gió mùa vào khoảng vài chục $\mathrm{cm}$ [6]. Dựa trên kết quả phân tích trong nhiều năm tại các trạm quan trắc thủy triều, Hoàng Trung Thành (2011) nhận định rằng, trong các đợt gió mùa mạnh, nước dâng do gió mùa có độ lớn từ $30-40 \mathrm{~cm}$, nhưng nhìn chung là nhỏ hơn $50 \mathrm{~cm}$ [7]. Nguyễn Bá Thủy trong nghiên cứu về nước dâng dị thường (do gió mùa) bằng mô hình số trị đã đánh giá rằng, phần lớn các đợt gió mùa gây nước dâng từ 20 đến $30 \mathrm{~cm}$, các trường hợp nước dâng lớn hơn $40 \mathrm{~cm}$ thường xảy ra trong thời kỳ gió mùa mùa Đông (tháng 10 và tháng 11 ) tại khu vực ven biển Đông Nam Bộ [8].

Ngày 3 tháng 8 năm 2019, mực nước biển 
dâng cao và sóng đã tràn qua tuyến đê phòng hộ ven biển thuộc xã Khánh Bình Tây, huyện Trần Văn Thời (Cà Mau), gây sạt lở thân đê một đoạn dài trên $300 \mathrm{~m}$. Nhiều đoạn đê khác trên tuyến đê biển Tây Nam Bộ cũng bị sạt lở nghiêm trọng. Đây là hiện tượng bất thường tại khu vực gây thiệt hại cho hàng chục nghìn ha lúa và cuộc sống của hàng chục nghìn hộ dân bị ảnh hưởng. Nhằm đánh giá nguyên nhân gây ra hiện tượng mực nước dâng cao bất thường trong thời gian trên, nghiên cứu này đã tính toán phục hồi mực nước tổng cộng tại khu vực biển Tây Nam bộ trên cơ sở sử dụng bộ mô hình số trị kết hợp giữa mô hình khí tượng và thủy động lực. Các yếu tố gió, sóng và thủy triều tại khu vực trong thời điểm đó sẽ được phân tích, đánh giá nhằm làm rõ sự đóng góp vào mực nước tổng cộng của các thành phần.

\section{Phương pháp nghiên cứu}

\subsection{Quy trình tính toán mục nước tổng cộng trong gió mùa}

Có năm yếu tố khác nhau có thể gây nên sự thay đổi mực nước ở các khu vực ven biển: (i) ảnh hưởng của áp suất khí quyển, (ii) ảnh hưởng trực tiếp của gió, (iii) ảnh hưởng của chuyển động quay của trái đất, (iv) ảnh hưởng của sóng, và (v) ảnh hưởng của mưa. Pore (1965) đã bổ sung hai thành phần là: (i) ảnh hưởng của độ lớn thủy triều và (ii) ảnh hưởng của hình dạng đường bờ và độ sâu biển [4].

Nghiên cứu sử dụng cách tiếp cận tính mực nước tổng cộng trên cơ sở tính toán riêng rẽ các thành phần của mực nước tổng cộng, cách tiếp cận này cho ta kết quả mực nước cực trị gần với thực tế hơn vì chúng thường được kiểm chứng độc lập theo từng quá trình $[5,9]$. Với cách tiếp cận này, mực nước tổng cộng tại khu vực biển Tây Nam bộ, trường gió tái phân tích trong khoảng thời gian từ ngày 01 đến $05 / 8 / 2019$ được tính toán bằng mô hình WRF để làm biên đầu vào cho mô hình thủy động lực và mô hình sóng. Mô hình MIKE 21 FM của Viện Thủy lực Đan
Mạch được sử dụng để tính toán thủy triều và nước dâng do gió. Đây là thủy động lực hai chiều áp dụng phương pháp phần tử hữu hạn, lưới phi cấu trúc có tính linh hoạt cao, rất phù hợp để áp dụng cho các khu vực cửa sông ven biển. Mô hình MIKE $21 \mathrm{SW}$ được sử dụng để tính toán trường sóng, mô hình này dựa trên nguyên tắc các sóng được mô tả bằng phổ mật độ của tác động sóng hai chiều sẽ được sử dụng để mô phỏng trường sóng trong bão. Lý thuyết và khả năng sử dụng các mô hình có thể tìm thấy trong các nghiên cứu trước [2]. Để tính toán nước dâng do sóng cho các điểm ven bờ, nghiên cứu này sử dụng kết quả nghiên cứu của Hanslow và Nielson (1993) dựa trên kết quả đo đạc độ cao nước dâng do sóng tại 4 bãi biển trong các điều kiện sóng khác nhau [3]. Sơ đồ quy trình tính toán mực nước tổng cộng trong gió mùa được đưa ra trong Hình 1.

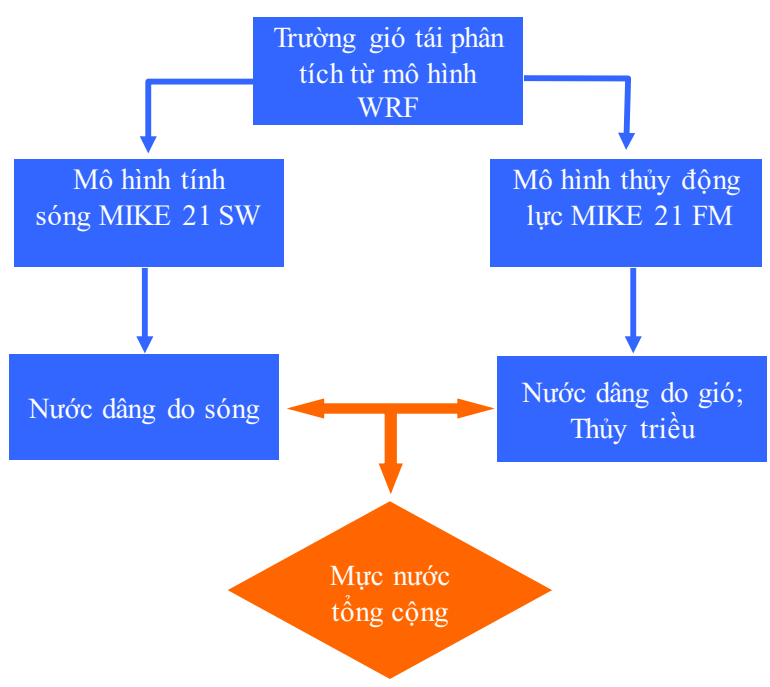

Hình 1. Quy trình tính mục nước tổng cộng

\subsection{Thiết lập miền tính và điều kiện tính} toán

Miền tính là toàn miền tính trên khu vực biển Đông với lưới phi cấu trúc gồm 35260 nút lưới, chiều dài của cạnh mắt lưới nhỏ nhất ở khu vực ven biển Tây Nam Bộ là 100 m (khu vực ven biển Tây Nam Bộ (Hình 2a-2b). 


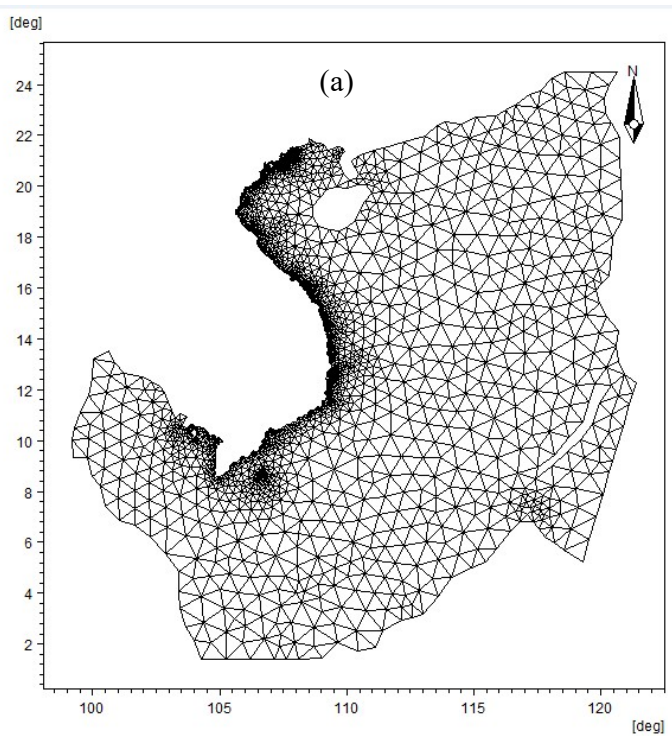

(b)

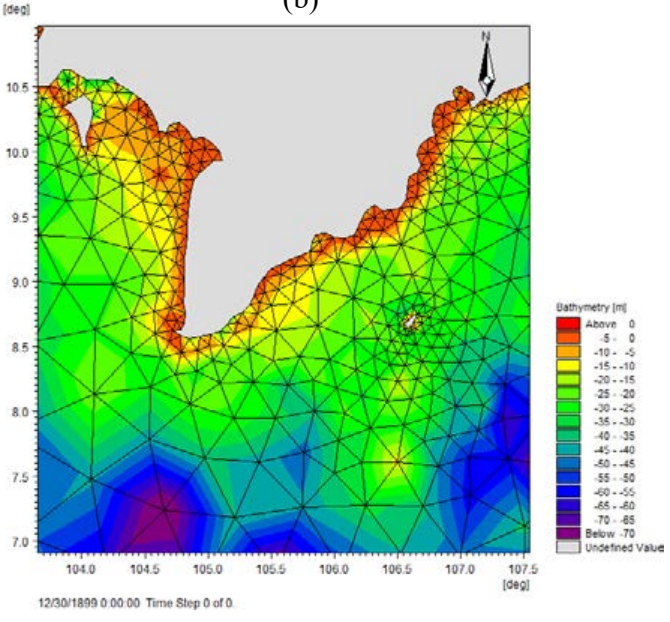

Hình 2. Miền tính (a) toàn khu vực biển Đông và (b) vùng biển Tây Nam Bộ

Địa hình miền tính được lấy từ hải đồ tỷ lệ khác nhau do Bộ Tư lệnh Hải quân và Cục đo đạc bản đồ, Bộ Tài nguyên và Môi trường cung cấp, biên ngoài khơi được lấy theo hằng số điều hòa từ bộ hằng số điều hòa trên toàn cầu của mô hình MIKE.

\subsection{Hiệu chỉnh và kiểm nghiệm}

a) Kiểm nghiệm mô hình thủy động lực

Mô hình thủy động lực MIKE $21 \mathrm{FM}$ được hiệu chỉnh với số liệu mực nước được tính từ phân tích điều hòa thủy triều trong thời gian từ 1 đến 14 tháng 1 năm 2018 tại khu vực ven biển Rạch Giá. Kết quả so sánh giữa số liệu tính toán và mực nước triều từ phân tích điều hòa tại Rạch Giá cho thấy có sự tương đồng cao về độ lớn và pha giữa kết quả mô phỏng và số liệu phân tích điều hòa, hệ số tương quan $\mathrm{R}$ giữa chuỗi số liệu tính toán và phân tích điều hòa $R$ đạt 0,96 (Hình 3).
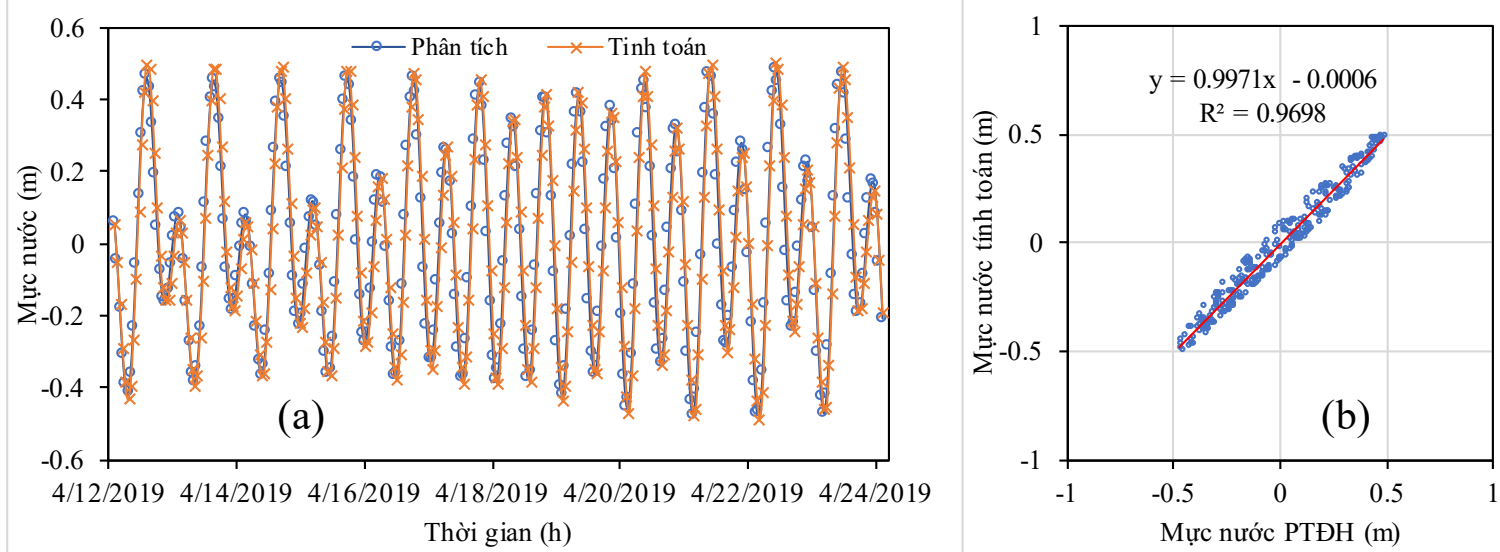

Hình 3. Hiệu chỉnh mục nước tại trạm Rạch Giá: (a) Biến trình mưc nước; (b) Hệ số tuoong quan

Mô hình tiếp tục được kiểm nghiệm với các thông số đã được hiệu chỉnh. Số liệu mực nước để kiểm nghiệm là số liệu của Trung tâm Nghiên cứu Thủy văn và Hải văn, Viện Khoa học Khí tượng Thủy văn và Biến đổi khí hậu đo đạc tại khu vực Rạch Giá bằng máy $\mathrm{AWAC}$ trong thời gian từ 13 đến 20 tháng 4 năm 2019. Kết quả so sánh giữa số liệu tính toán và thực đo tại Rạch Giá bằng máy $\mathrm{AWAC}$ cho thấy có sự tương đồng cao về độ lớn và pha giữa kết quả mô phỏng và số liệu thực đo với hệ số tương quan $\mathrm{R}$ đạt 0.801 (Hình 4). 


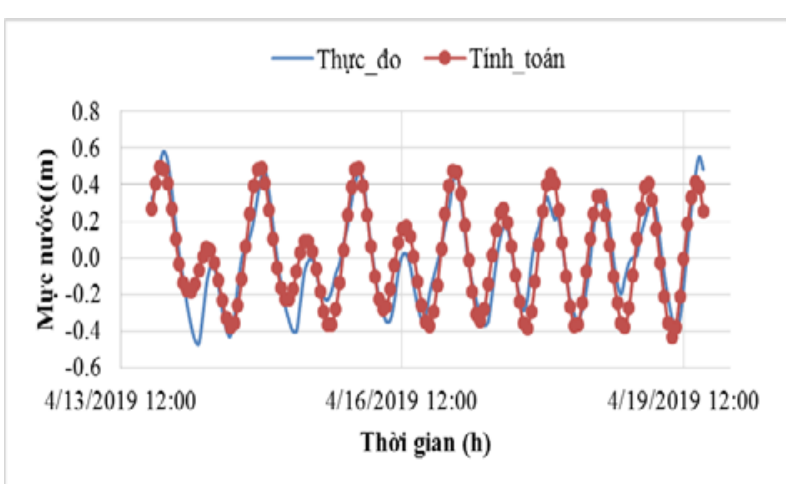

(a) Biến trình mực nước

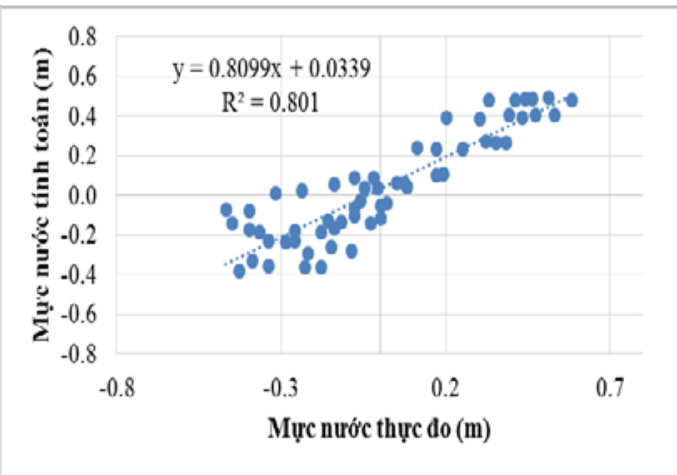

(b) Hệ số tương quan

Hình 4. Kiểm nghiệm mục nước với số liệu thực đo tù máy $A W A C$

Căn cứ vào kết quả kiểm nghiệm cho thấy các thông số mô hình MIKE 21 FM đã ổn định, mô phỏng khá tốt chế độ thuỷ lực tại khu vực biển Tây Nam Bộ. Bộ thông số sau khi được kiểm nghiệm sẽ được sử dụng để tính toán mực nước tổng cộng trong đợt gió mùa từ ngày 02 đến ngày 04 tháng 8 năm 2019.

\section{b) Kiểm nghiệm mô hình sóng}

Mô hình MIKE $21 \mathrm{SW}$ được kiểm nghiệm với số liệu độ cao sóng tại khu vực ngoài khơi Tây Nam Bộ. Số liệu sóng để kiểm nghiệm là số liệu của Trung tâm Nghiên cứu Thủy văn và Hải văn, Viện Khoa học Khí tượng Thủy văn và Biến đổi khí hậu đo đạc bằng máy $\mathrm{AWAC}$ trong thời gian từ 13 đến 20 tháng 4 năm 2019 .

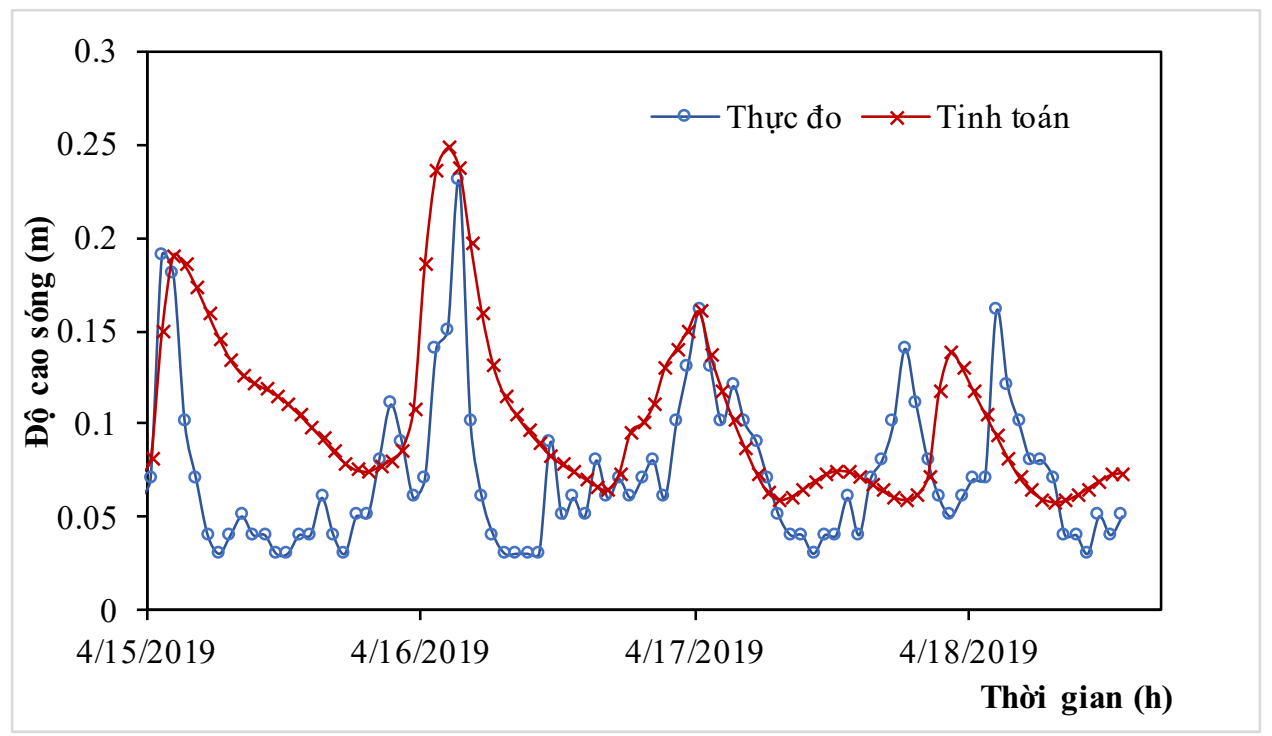

Hình 5. Kiểm nghiệm mô hình sóng

Các kết quả kiểm nghiệm trong Hình 5 cho thấy có sự phù hợp khá tốt của giá trị độ cao sóng cực đại tính toán và đo đạc từ các trạm phao theo thời gian, kết quả kiểm tra cho thấy, sai số tuyệt đối đạt $0,017 \mathrm{~m}$, trung bình giá trị BIAS giữa chuỗi tính toán và thực đo là $-0.06 \mathrm{~m}$ có giá trị âm, nghĩa là độ cáo sóng tính toán có xu thế lớn hơn số liệu thực đo, trung bình giá trị RMS là $0.07 \mathrm{~m}$. Các có thể chấp nhận được với tính toán mô phỏng sóng (Bảng 1). 
Hình 3. Địa hình vùng cưa sông và mặt cắt sông Vệ

\begin{tabular}{lc}
\hline \multicolumn{1}{c}{ Yếu tố } & Giá trị \\
\hline Độ cao sóng cao nhất thực đo $(\mathrm{m})$ & 0,23 \\
Độ cao sóng cao nhất tính toán $(\mathrm{m})$ & 0,247 \\
Sai số tuyệt đối (m) & 0,017 \\
Sai số tương đối (\%) & 7,8 \\
Thời gian lệch đỉnh (giờ) & 1 \\
Hệ số tương quan & 0,42 \\
BIAS (m) & 0,06 \\
RMS (m) & 0,07 \\
\hline
\end{tabular}

\section{Kết quả và thảo luận}

Phương pháp mực nước tổng cộng trong gió mùa sau khi đã được hiệu chỉnh và kiểm nghiệm ở trên được sử dụng để mô phỏng tính toán mực nước tổng cộng trong đợt gió mùa từ ngày 02 đến ngày 04 tháng 8 năm 2019 cho một số vị trí đại diện cho các điểm ven bờ biển khu vực tỉnh Kiên Giang và Cà Mau (Hình 6).

Kết quả tính toán cho thấy, thủy triều tại khu vực ven biển Tây Nam Bộ là nhật triều không đều với 1 lần nước lên xuống trong ngày. Trong thời gian từ 02 đến 04 tháng 8 năm 2019, có biên độ triều trong khu vực tăng dần từ Hà Tiên đến mũi Cà Mau với biên độ triều trong khoảng từ $0,7-1,3 \mathrm{~m}$. Thủy triều đạt cực trị vào lúc $15 \mathrm{~h}$ ngày 03 tháng 8 năm 2019, mực nước triều (so với cao độ quốc gia) tại các vị trí ven biển huyện Kiên Lương, Tp. Rạch Giá, huyện U Minh và

1.54 m và $1.59 \mathrm{~m}$ (Hình 7 , Bảng 2 ).

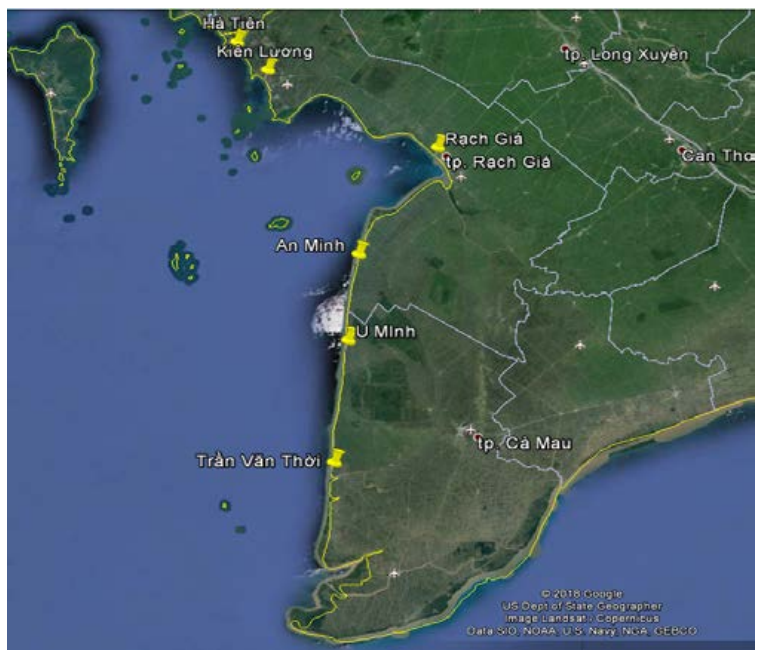

Hình 6. Các vị trí tính nước dâng tổng cộng khu vục ven biển Tây Nam Bộ

(1) Kiên Luoong; (2) Rạch Giá; (3) U Minh; (4) Trần Văn Thời huyện Trần Văn Thời lần lượt là 1.36m, 1.49m,

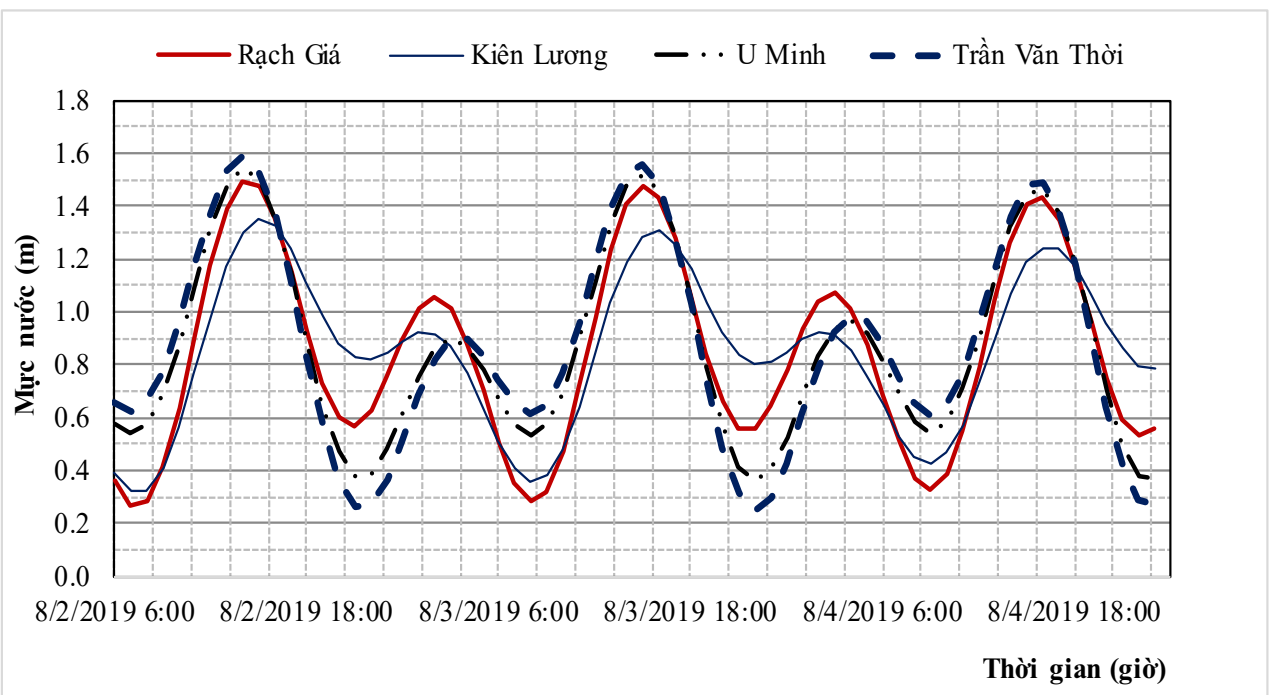

Hình 7. Phân bố theo không gian và biến trình độ lớn thủy triều 
Gió mùa Tây Nam duy trì thời gian dài với vận tốc lên tới trên $10 \mathrm{~m} / \mathrm{s}$ ngoài khơi là nguyên nhân gây ra sóng tại khu vực này khá lớn, độ cao sóng lớn nhất tại khu vực ven biển Tây Nam Bộ lên tới trên $2,5 \mathrm{~m}$. Độ cao sóng lớn nhất ngoài
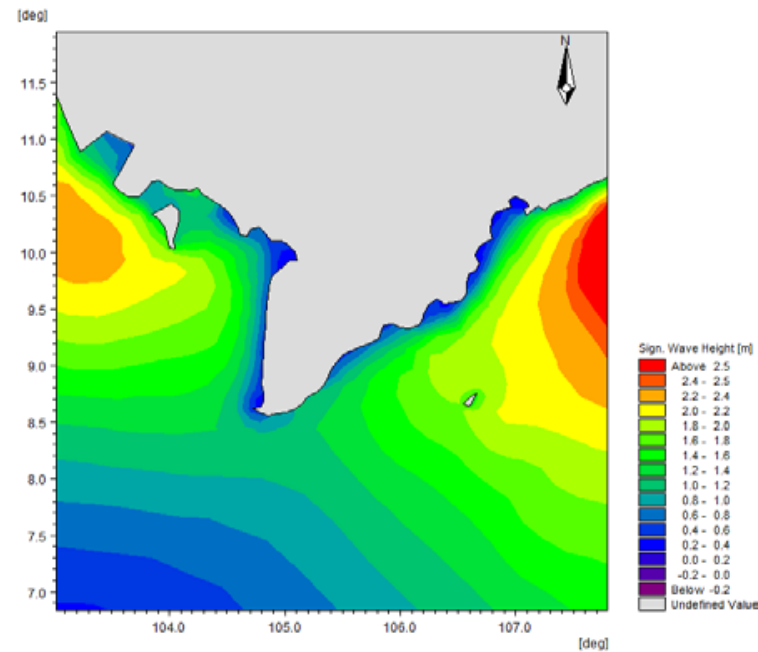

khơi khu vực ven biển huyện Kiên Lương, Tp. Rạch Giá, huyện U Minh và huyện Trần Văn Thời lần lượt là $1,64 \mathrm{~m}, 1,62 \mathrm{~m}, 1,98 \mathrm{~m}$ và $2,44 \mathrm{~m}$ (Hình 8, Bảng 2).

Hình 8. Phân bố theo không gian và biến trình độ cao sóng

Sóng cao và có thời gian duy trì dài gây ra nước dâng do sóng tại khu vực này khá lớn. Nước dâng do sóng tại khu vực ven biển Tây Nam Bộ phụ thuộc vào độ cao sóng có nghĩa ngoài khơi và địa hình tại các điểm cần tính. Nước dâng do sóng lớn nhất tại khu vực trong thời kỳ tính toán có thể lên đến $0,25 \mathrm{~m}$. Nước dâng do sóng lớn nhất khu vực ven biển huyện Kiên Lương, Tp. Rạch Giá, huyện U Minh và huyện Trần Văn Thời lần lượt là $0,20 \mathrm{~m}, 0,19 \mathrm{~m}, 0,18 \mathrm{~m}$ và $0,22 \mathrm{~m}$ (Bảng 2$)$.

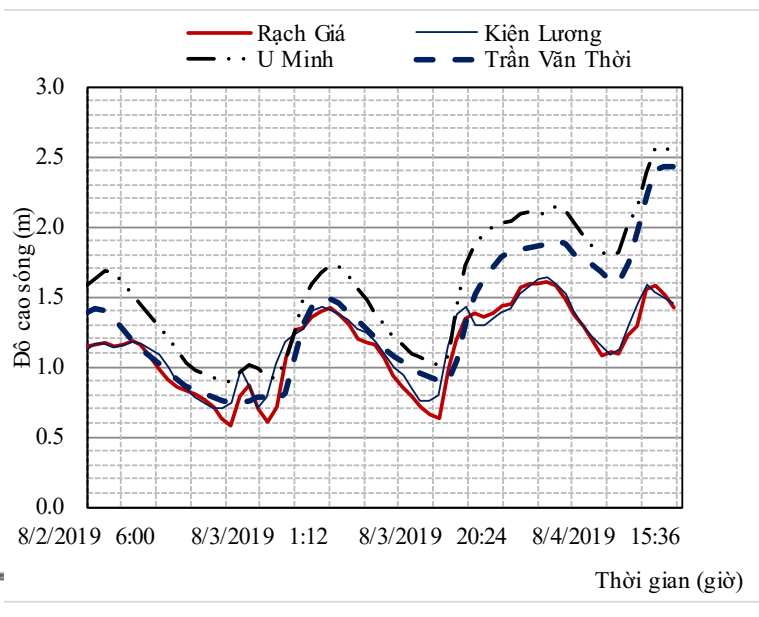

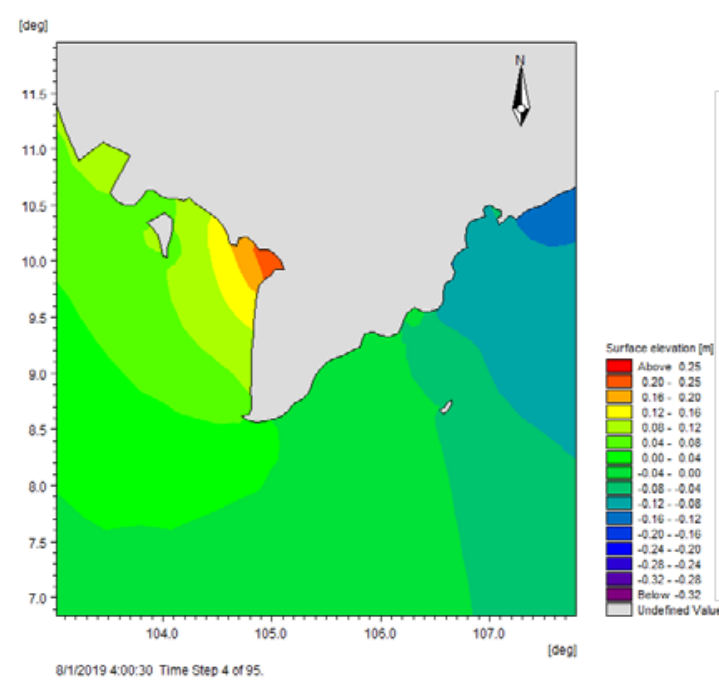

Kết quả tính toán cho thấy, nước dâng do gió tại khu vực Tây Nam Bộ có xu hướng dồn nước tại khu vực ven biển Rạch Giá do địa hình lõm của Vịnh Rạch Giá và hoạt động mạnh và ổn định, thổi vuông góc với hướng bờ của gió mùa Tây Nam. Nước dâng do gió lớn nhất khu vực ven biển huyện Kiên Lương, Tp. Rạch Giá, huyện U Minh và huyện Trần Văn Thời lần lượt là $0,52 \mathrm{~m}$, $0,66 \mathrm{~m}, 0,47 \mathrm{~m}$ và $0,38 \mathrm{~m}$ (Hình 9 , Bảng 2 )

Hình 9. Phân bố theo không gian và biến trình độ lớn nước dâng do gió 
Kết quả tính toán mực nước tổng cộng và các thành phần đóng góp vào mực nước tổng cộng cho thấy, tại khu vực đê biển huyện Trần Văn Thời, Cà Mau, nước dâng do gió mùa Tây Nam Bộ và thủy triều gần như đạt giá trị lớn nhất tại cùng một thời điểm nhưng không cùng với thời gian đạt mực nước lớn nhất của nước dâng do sóng, nước dâng tổng cộng lớn nhất trùng với thời điểm mực nước triều lớn nhất. Mực nước tổng cộng trong gió mùa tại khu vực này lớn nhất lúc 15 h ngày 02 tháng 8 năm 2019 đạt $2,05 \mathrm{~m}$ (Hình 9). Đê biển huyện Trần Văn Thời có cao trình đỉnh đê là $3 \mathrm{~m}$.

Bảng 2. Mực nước tổng cộng lớn nhất và các thành phần tại khu vục Tây Nam Bộ

\begin{tabular}{cccccc}
\hline TT & $\begin{array}{c}\text { Khu vực } \\
\text { ven biển }\end{array}$ & $\begin{array}{c}\text { Thủy triều } \\
\text { cao nhất }(\mathrm{m})\end{array}$ & $\begin{array}{c}\text { Nước dâng doNước dâng do } \\
\text { gió } \\
\text { lớn nhất }(\mathrm{m})\end{array}$ & $\begin{array}{c}\text { Mực nước } \\
\text { lớng } \\
\text { nhất }(\mathrm{m})\end{array}$ & $\begin{array}{c}\text { tống cộng } \\
\text { lớn nhât }(\mathrm{m})\end{array}$ \\
\hline 1 & Kiên Lương & 1,36 & 0,52 & 0,20 & 1,92 \\
2 & Rạch Giá & 1,49 & 0,66 & 0,19 & 2,13 \\
3 & An Minh & 1,54 & 0,47 & 0,18 & 2,12 \\
4 & Trần Văn Thời & 1,59 & 0,38 & 0,22 & 2,05 \\
\hline
\end{tabular}

Như vậy, mực nước biển dâng cao do các nguyên nhân trên kết hợp với sóng lớn tại khu vực là nguyên nhân chính gây tràn đê tại khu vực này. Các vị trí khác tại khu vực ven biển Tây Nam Bộ cũng xấp xỉ $2 \mathrm{~m}$, ven biển huyện Kiên Lương, TP. Rạch Giá và huyện U Minh với có giá trị lần lượt là $1,92 \mathrm{~m}, 2,13 \mathrm{~m}$ và $2,12 \mathrm{~m}$ (Bảng 2$)$.

\section{Kết luận và kiến nghị}

Nghiên cứu đã tính nước dâng tổng cộng trong gió mùa Tây Nam Bộ với bộ công cụ là các mô hình số trị đã được kiểm chứng với số liệu thực đo. Kết quả tính toán cho thấy, tại các điểm ven bờ, nước dâng tổng cộng trong bão có sự đóng góp của nhiều yếu tố, trong đó có thủy triều; nước dâng do gió và nước dâng do sóng. Mực nước tổng cộng trong gió mùa tại khu vực này trong khoảng thời gian từ 02 đến 04 tháng 8 năm 2019 đạt xấp xỉ $2 \mathrm{~m}$, trong đó nước dâng do gió mùa đóng góp từ $0,35-0,5 \mathrm{~m}$, nước dâng do sóng từ $0,1-0,25 \mathrm{~m}$, còn lại là mực nước triều. Mực nước biển dâng cao do các nguyên nhân trên kết hợp với sóng triều tại khu vực cao từ 2 $2,5 \mathrm{~m}$ là nguyên nhân chính gây tràn đê tại khu vực huyện Trần Văn Thời.

Đê biển Tây Nam Bộ là tuyến đê phòng hộ ven biển có vai trò rất quan trọng để ngăn mặn, bảo vệ sản xuất. Mặc dù đã được gia cố đến cao trình $3,0 \mathrm{~m}$ nhưng với diễn biến bất thường của thời tiết và ảnh hưởng của mực nước biển dâng do biến đổi khí hậu, cần phải có các giải pháp để đảm bảo an toàn đê biển trong tương lai. Thứ nhất, cần có các giải pháp trồng rừng ngập mặn trước đê tại khu vực này nhằm tiêu tán năng lượng sóng biển. Thứ hai, cần có các nghiên cứu, tính toán lại mực nước thiết kế đê đảm bảo an toàn cho công trình trong tương lai.

\section{Tài liệu tham khảo}

1. Chương trình điều tra nghiên cứu biển cấp nhà nước NCKH-06 (2003), Biển Đông, Tập II, Khí tượng Thủy văn Động lực biển, Nhà xuất bản Đại học Quốc gia Hà Nội, Hà Nội.

2. DHI (2017), Mike $21 \&$ Mike 3 flow model FM_Hydrodynamic and transport module-Scientific Documentation.

3. Hanslow, D.J., Nielsen, P. (1992), Wave setup on beaches and in river entrances. Proceedings of 23rd International Conference on Coastal Engineering, 240-252.

4. Harris, D.L. (1963), Characteristics of the Hurricane Storm Surge, United States Department of Commerce, Washington D.C, United States. 


\title{
BÀI BÁO KHOA HỌC
}

5. Nguyễn Xuân Hiển (2013), Nghiên cưu nước dâng do bão có tính đến ảnh hưởng của sóng và áp dụng cho khu vực ven biển Hải Phòng, Luận án Tiến sỹ.

6. Phạm Văn Huấn (1991), Dao động tụ do của mực nước ở biển Đông. Tạp chí Các khoa học về trái đất, 4 (T.13), tr. 113-116.

7. Hoàng Trung Thành (2011), Nghiên cứu đặc điểm biến thiên mực nước biển ven bờ Việt Nam, Luận án Tiến sĩ, Hà Nội.

8. Nguyễn Bá Thủy, Trần Quang Tiến (2017), Nghiên cứu nước dâng trong các đợt triều cường tại ven biển đông Nam Bộ, Tạp chí Khí tượng Thủy văn, 683, 11/2017, tr. 29-36.

9. Đinh Văn Ưu và nnk. Đánh giá biến động mực nước biển cực trị do ảnh huơong của biến đổi khi hậu phuc vu chiến lược kinh tế biển. Báo cáo tổng kết đề tài KC-09.23/06-10, Chương trình biển, Hà nội, 2010.

10. Nguyễn Văn Viết (1984), Đặc điểm khi hậu vùng biển Việt Nam, NXB. Bộ Tư lệnh Hải quân.

11. https://www.ecmwf.int/;

12. http://www.jma.go.jp/jma/indexe.html;

13. https://www.met.no/en.

\section{UNFAVORABLE COMBINATION OF SOUTHWEAT MONSOON AND TIDE ON SEA DYKE IN THE SOUTHWESTERN REGION ON AUGUST 3RD, 2019}

\author{
Nguyen Xuan Hien', Le Duc Quyen ${ }^{1}$ \\ ${ }^{1}$ Viet Nam Institute of Meteorology, Hydrology and Climate Change
}

\begin{abstract}
Monsoon induced water surge affects the safety and integrety of coastal structures. This is especially true during high tide. In early August 2019, the sea dike system in the coastal area of Tran Van Thoi district exhibited wave spillover, creating serious landslides phenomenon, affecting dike safety, damaging a large area of rice cultivation and adversely affecting a large number of households. The numerical model is applied to calculate and evaluate the contribution of the southwest monsoon induced water surge, wave induced water surges, tidal water level, and the total water level that created water spillover in early August 2019. The results show that, the highest total water level in the first 2 days during the monsoon event of August 2019 in the South West coastal area reached up to $2 \mathrm{~m}$ in height. Of whcih, monsoon induced water surge contributes between 0.35 to $0.5 \mathrm{~m}$, wave induced water surges from 0.1 to $0.25 \mathrm{~m}$, tide levels are 1.3 to $1.6 \mathrm{~m}$ towards total water level. Sea level surged due to the aforementioned components reaching as high as $2-2.5 \mathrm{~m}$ and is the major cause of dike spillover in the area.
\end{abstract}

Keywords: Total surges, monsoon surge, wave surge, wave height, tide. 